\title{
Bovine brucellosis trends in Malaysia between 2000 and 2008
}

\author{
Mukhtar S Anka', Latiffah Hassan ${ }^{1 *}$, Azri Adzhar², Siti Khairani-Bejo ${ }^{1}$, Ramlan Bin Mohamad³ and Mohamed A Zainal ${ }^{4}$
}

\begin{abstract}
Background: Bovine brucellosis is an important disease affecting cattle characterised by abortion, still birth, reduced milk production, weak foetus and infertility in both males and females. There is wide distribution of the disease among cattle and several wildlife species. Bovine brucellosis is commonly caused by B. abortus and very occasionally B. melitensis and B. suis. The distribution of bovine brucellosis in cattle has not been described in Malaysia. In this paper we describe the distribution, pattern and trend of bovine brucellosis in Peninsular Malaysia between 2000 and 2008 based on serological data obtained from nationwide B. abortus serosurveillance activities in cattle populations.

Results: Brucella antibodies were detected in $21.8 \%$ of sampled herds $(95 \% \mathrm{Cl}, 21.01-22.59)$ and $2.5 \%$ (95\% Cl; 2.45-2.55) of sampled cattle. The state of Pahang had the highest animal and herd-level seroprevalence of 5.3 and $43.6 \%$, respectively. The herd-level seroprevalence varied but remained high (18-26\%) over the period of study and generally increased from 2000 to 2008. Seropositive herds clustered around the central part of the peninsula within the period of the study. The months of September, October and November illustrated the highest rates with corresponding seroprevalences of 33.2, 38.4 and 33.9\%, respectively. A noticeable variation was observed in the cattle-level seroprevalence, but the rate remained relatively low $(<5 \%)$. The chi-square statistics showed herd size $(x 2=1206.077, d f=2, p=0.001)$, breed $(x 2=37.429, d f=1, p=0.001)$, month of sampling $(x 2=51.596, d f=11$ $p=0.001)$, year $(x 2=40.08, d f=8, p=0.001)$ and state $(x 2=541.038, d f=10, p=0.001)$ to be associated with increased seropositivity.
\end{abstract}

Conclusion: Bovine brucellosis is widespread among herds in Peninsular Malaysia at a low within-herd seroprevalence rate.

Keywords: Epidemiology, Bovine brucellosis, Distribution, Trend, Pattern

\section{Background}

Bovine brucellosis continues to be a common zoonosis disease with a significant economic impact in livestock that is widely distributed among cattle and related wildlife species worldwide [1-3]. The disease is primarily caused by $B$. abortus and occasionally B. melitensis and B. suis. Most human brucellosis cases, however, have been linked to B. melitensis [4]. Bovine brucellosis is characterised by abortion, still birth, infertility and reproductive failure [5]. Humans may contract the infection via direct contact of contaminated materials or drinking raw milk from affected cows [6]. In recent years, several outbreaks of brucellosis

\footnotetext{
*Correspondence: latiffah@upm.edu.my

'Department of Veterinary Pathology and Microbiology, Faculty of Veterinary Medicine, Universiti Putra Malaysia, UPM, Serdang 43400, Malaysia Full list of author information is available at the end of the article
}

have been reported among humans in Malaysia, mainly due to the consumption of raw goat's milk contaminated with $B$. melitensis $[7,8]$. Elsewhere, many brucellosis cases in humans have been attributed to drinking raw cow's milk $[9,10]$.

Bovine brucellosis was first identified in Malaysia in 1950 [11]. The spread of the disease later instigated a nationwide brucellosis eradication programme, which involved the testing and slaughter of seropositive animals and consequently resulted in a marked decline in the number of seropositive cattle [12]. Much success has been achieved through this programme and, consequently, resulted in a marked reduction in the number of seropositive cattle from $8.7 \%$ in 1980 to $0.4 \%$ in 1993 [13].

In many countries, serological testing followed by culling has been practiced to control brucellosis with varying 
levels of success [14]. In an effort committed to tackling the problem, the Malaysian veterinary authorities have conducted an active serosurveillance of bovine brucellosis for many years. The exercise is routinely followed by culling of infected animals with compensation to the farmers [12]. Previous surveys have established that bovine brucellosis may be hypoendemic but still occurs in many parts of the peninsula [15-18]. However, in the last decade, anecdotal evidence suggests an increase of brucellosis infection among cattle. In this study, we describe the trends and pattern of brucellosis among cattle in the past decade from a retrospective analysis of data collected from a nationwide brucellosis active surveillance programme. We believe that information from this study will enhance understanding about the epidemiology of bovine brucellosis in Peninsular Malaysia and assist the authorities in improving their disease-control strategies.

\section{Results}

A total of 10,584 herds and 407,646 cattle were sampled within the period of study (2000-2008), of which 2,302 (21.8\%; 95\% CI, 21.01-22.59) herds and 10,013 (2.5\%; 95\% CI; 2.45-2.55) cattle tested positive. The annual mean seroprevalence level among cattle for the period of study was $2.7 \%$, with 2008 having the highest rate (4.2\% CI, 3.96-4.44) and 2004 having the lowest (1.1\% CI, 1.031.17) (Figure 1). A significant decreasing trend of seroprevalence from 2000 to 2004 and increasing trend from 2004 to 2008 was observed $\left(\chi^{2}=40.08, \mathrm{df}=8, p=0.001\right)$ (Figure 1). Among the states, the highest cattle-level seroprevalence was observed in Pahang at 5.4\% (95\% CI, 4.76-
5.84) and the lowest in Pulau Pinang at 1.2\% (95\% CI, 1.05-1.55) (Table 1).

The range of prevalence within the seropositive herds was 0.9 to $100 \%$ from an average herd size of 41 cattle. The annual mean seroprevalence for the study period was $21.7 \%$ with the highest in 2007 (26.9\% CI, 24.4429.36) and the lowest in 2000 and 2001 (18.6\% CI, 16.44-20.76) (Figure 1). Table 1 shows the bovine brucellosis seroprevalence within each state. The herd-level seroprevalence rates among the states were significantly different $\left(\chi^{2}=541.038, \mathrm{df}=10, p=0.001\right)$. The highest herd level seroprevalence was observed in Pahang at 45.4\% (95\% CI, 35.75-51.85) and the lowest in Melaka at 10.7\% (95\% CI, 8.89-12.71). The herd-level seroprevalence rates varied between months within the study years, showing a significant increasing trend within the year. The months of September, October and November had the highest rates with corresponding seroprevalences of 33.2, 38.4 and $33.9 \%$, respectively. The differences between the months were significant $\left(\chi^{2}=51.596\right.$, $\mathrm{df}=11 p=0.001)$ (Figure 2).

Herd size was associated with the herd-level seroprevalence $\left(\chi^{2}=1206.077, \mathrm{df}=2, p=0.001\right)$ whereby larger herds had a higher likelihood of being seropositive. Table 1 shows the detailed descriptive and univariate analysis of herd-level data. Breeds were also associated with increased seropositivity ( $\mathrm{X} 2=37.429, \mathrm{df}=1, p=0.001)$ and beef cattle appeared to be at higher risk for seroreaction. Brahman, Bali, Kedah Kelantan and Nellore cattle had a higher likelihood of seropositivity while dairy breeds such as Friesien-Sahiwal and LID had significantly lower likelihoods (Table 1).

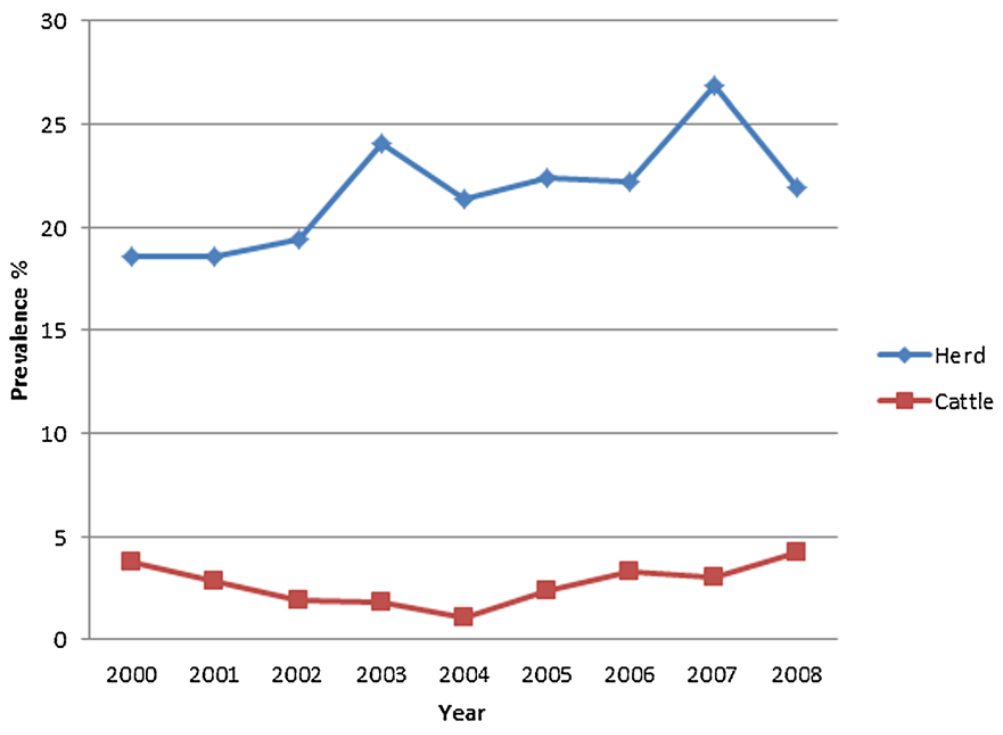

Figure 1 Annual herd-level and cattle seroprevalence of bovine brucellosis in Peninsular Malaysia from 2000 to 2008. 
Table 1 Herd-level seroprevalence of bovine brucellosis based on several factors in Peninsular Malaysia between 2000 and 2008

\begin{tabular}{|c|c|c|c|c|c|c|}
\hline Variables & Categories & $\mathrm{N}$ & Prevalence (\%) & OR & $95 \% \mathrm{Cl}$ & P-value \\
\hline \multirow[t]{9}{*}{ Year } & 2000 & 1245 & 18.6 & Ref & - & - \\
\hline & 2001 & 1227 & 18.6 & 1.00 & $0.818-1.227$ & 0.986 \\
\hline & 2002 & 1161 & 19.9 & 1.09 & $0.890-1.336$ & 0.404 \\
\hline & 2003 & 1427 & 20.4 & 1.12 & $0.928-1.363$ & 0.232 \\
\hline & 2004 & 1140 & 21.5 & 1.20 & $0.983-1.469$ & 0.073 \\
\hline & 2005 & 934 & 22.4 & 1.27 & $1.026-1.561$ & 0.028 \\
\hline & 2006 & 1289 & 22.1 & 1.25 & $1.026-1.513$ & 0.026 \\
\hline & 2007 & 1249 & 26.8 & 1.61 & $1.331-1.945$ & 0.001 \\
\hline & 2008 & 923 & 23.8 & 1.37 & $1.116-1.692$ & 0.003 \\
\hline \multirow[t]{12}{*}{ Month of sampling } & January & 476 & 17.2 & Ref & - & - \\
\hline & February & 729 & 19.2 & 1.1 & $0.839-1.532$ & 0.415 \\
\hline & March & 1116 & 19.7 & 1.2 & $0.883-1.549$ & 0.270 \\
\hline & April & 1264 & 18.8 & 1.1 & $0.839-1.459$ & 0.475 \\
\hline & May & 1260 & 18.3 & 1.1 & $0.811-1.413$ & 0.631 \\
\hline & June & 1241 & 22.2 & 1.4 & $1.038-1.792$ & 0.026 \\
\hline & July & 1057 & 23.9 & 1.5 & $1.138-1.979$ & 0.004 \\
\hline & August & 1106 & 21.5 & 1.3 & $0.990-1.726$ & 0.059 \\
\hline & September & 762 & 24.9 & 1.6 & $1.186-2.115$ & 0.002 \\
\hline & October & 667 & 27.7 & 1.8 & $1.366-2.451$ & 0.001 \\
\hline & November & 502 & 25.3 & 1.6 & $1.182-2.206$ & 0.003 \\
\hline & December & 418 & 22.7 & 1.4 & $1.008-1.951$ & 0.045 \\
\hline \multirow[t]{11}{*}{ States } & Selangor & 1553 & 20.9 & Ref & - & - \\
\hline & Terengganu & 545 & 18.5 & 0.9 & $0.671-1.102$ & 0.232 \\
\hline & Perlis & 52 & 36.5 & 2.2 & $1.221-3.876$ & 0.008 \\
\hline & Perak & 1935 & 19.2 & 0.9 & $0.761-1.062$ & 0.212 \\
\hline & Pahang & 1318 & 43.6 & 2.9 & $2.475-3.454$ & 0.001 \\
\hline & Pulau Pinang & 109 & 11.9 & 0.5 & $0.283-0.925$ & 0.027 \\
\hline & N. Sembilan & 1171 & 14.4 & 0.6 & $0.520-0.781$ & 0.001 \\
\hline & Melaka & 1016 & 10.8 & 0.5 & $0.364-0.579$ & 0.001 \\
\hline & Kelantan & 663 & 28.1 & 1.5 & $1.196-1.816$ & 0.001 \\
\hline & Kedah & 626 & 15.3 & 0.7 & $0.533-0.878$ & 0.003 \\
\hline & Johor & 1607 & 19.3 & 0.9 & $0.759-1.075$ & 0.251 \\
\hline \multirow[t]{3}{*}{ Herd size } & $<20$ & 4328 & 9.0 & Ref & - & - \\
\hline & $20-40$ & 2101 & 27.5 & 3.1 & $2.660-3.510$ & 0.001 \\
\hline & $>40$ & 1891 & 69.2 & 7.7 & $6.794-8.731$ & 0.001 \\
\hline \multirow[t]{6}{*}{ Breed } & Kedah-Kelantan & 3291 & 27.7 & Ref & - & - \\
\hline & Bali & 25 & 36 & 1.5 & $0.648-3.342$ & 0.356 \\
\hline & Brahman & 283 & 38.9 & 1.7 & $1.294-2.138$ & 0.001 \\
\hline & Kedah-Kelantan cross & 3290 & 27.6 & 0.6 & $0.526-0.658$ & 0.001 \\
\hline & Local Indian Dairy & 3849 & 18.4 & 0.7 & $0.599-0.818$ & 0.001 \\
\hline & Nellore & 30 & 36.7 & 1.5 & $0.718-3.196$ & 0.276 \\
\hline
\end{tabular}


Table 1 Herd-level seroprevalence of bovine brucellosis based on several factors in Peninsular Malaysia between 2000 and 2008 (Continued)

\begin{tabular}{lllllll}
\hline & Sahiwal-Friesien & 1078 & 12.9 & 0.4 & $0.319-0.470$ & 0.001 \\
& Others & 69 & 4.4 & 0.1 & $0.037-0.379$ & 0.001 \\
Type of production & Dairy & 2333 & 17.2 & Ref & - & - \\
& Beef & 7538 & 23.2 & 1.45 & $1.288-1.638$ & 0.001 \\
\hline $\mathrm{Cl}=$ confidence interval, OR = odds ratio, Ref = reference group. & & &
\end{tabular}

\section{Spatial distribution}

The choropleth map (Figures 3, 4 and 5) shows the spatial distribution of bovine brucellosis based on year and cattle population size. It appears that the seroreactor herds tend to cluster around the central region of the peninsula with pockets of disease in the northern part of the peninsula.

\section{Discussion}

The herd-level brucellosis seroprevalence among the cattle population of Malaysia of $21.8 \%$ (95\% CI, 21.0122.59 ) is slightly lower than in neighbouring countries such as Indonesia and Thailand, with rates of 27.4 and $24.1 \%$, respectively $[19,20]$ and other countries in the world where the disease is endemic such as Brazil, Ethiopia and Jordan, which reported herd-level seroprevalence rates of 32.4, 26.1 and $23 \%$, respectively [21-23]. The cattle-level seroprevalence of $2.5 \%$ (95\% CI; $2.45-2.55)$ is also lower when compared to countries where the disease is endemic such as Thailand (3.3\%), Egypt (11\%), Brazil (3.2\%) and Nigeria (19.7\%) [20,22,24,25]. The observed disparity could be attributed to various factors that were not measured in this study but which we believe could be the result of different testing and protocols used for surveillance activities, the type of cattle-rearing management system, and the level of stringency in disease-control measures in the country. In our study, the overall within-herd seroprevalence of $2.5 \%$ is a marked reduction from $21 \%$ that was previously reported in a limited geographic and sample size study [18]. In addition, another study demonstrated the success achieved through a local eradication programme, whereby the national reactor rate declined from $8.7 \%$ in 1980 to $0.4 \%$ in 1993 [13].

Herd-level seroprevalence varied significantly over the 9 years of study and showed a gentle rising trend from 2000 to 2008 . We believe that the pattern observed was a function of the serosurveillance and culling activities within the affected herd. The testing and culling may have detected most of the seropositive cattle, but may have missed a small percentage, which subsequently propagated the infection to other animals and herds. Consistent with our beliefs, the cattle-level seroprevalence showed a dissimilar trend than the herd. There was a significant (3.8 to $1.1 \%$ ) reduction in the reactors

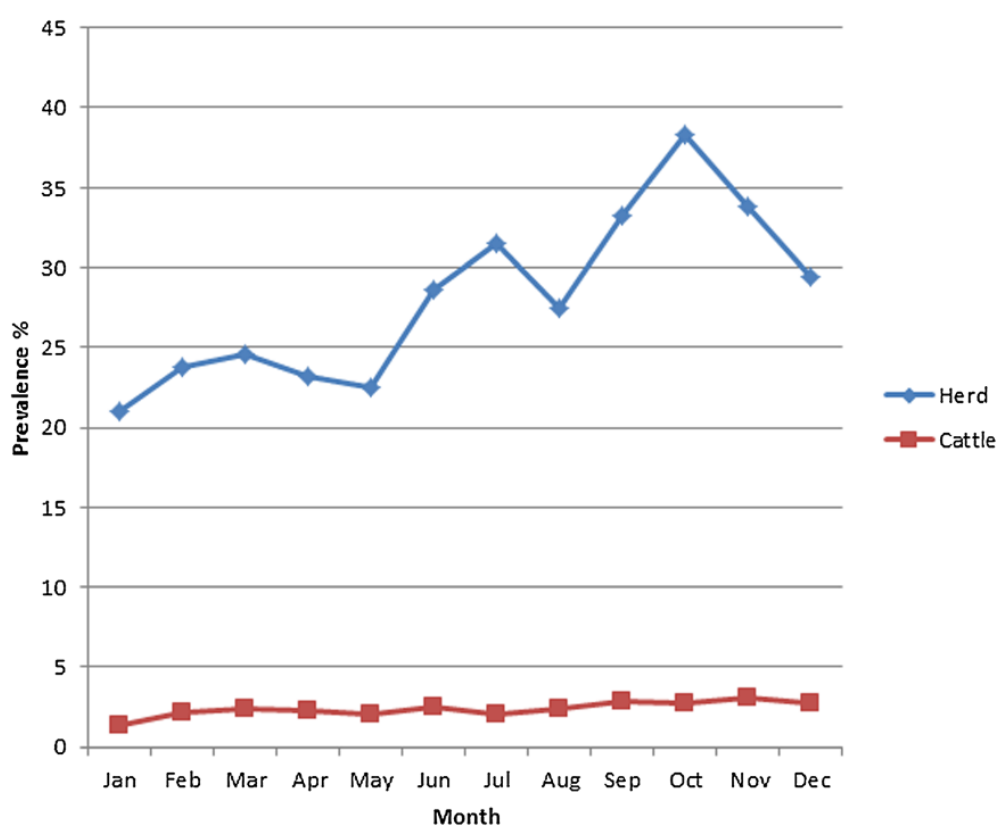

Figure 2 Monthly herd-level and cattle seroprevalence of bovine brucellosis in Peninsular Malaysia from 2000 to 2008. 


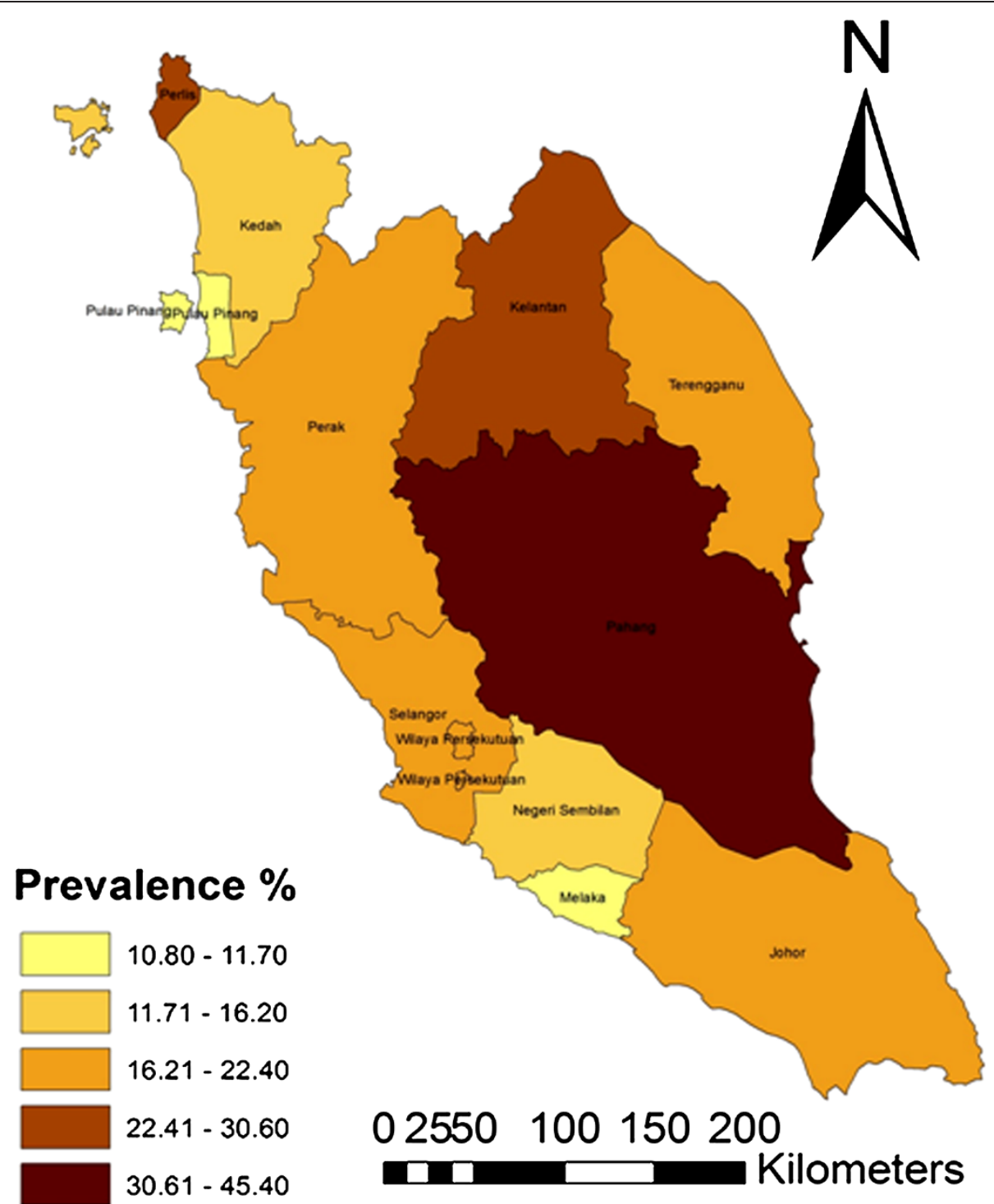

Figure 3 Choropleth map showing the overall prevalence of seropositive herd in Peninsular Malaysia between 2000 and 2008.

among cattle from 2000 to 2004, but thereafter the rate increased significantly (1.1 to $4.2 \%)$. We believe that this trend was a result of variations in the concentration of time and resources by the authorities, depending on the animal disease situation in the country. For example, the decrease in sero-reactor animals from 2000 onwards was possibly due to the intensification in controlling zoonotic diseases in the wake of the novel Nipah virus outbreak in 1998-1999 [26]. Unfortunately, from around 2004 until 2007, Malaysia suffered a few outbreaks of highly pathogenic avian influenza (HPAI), which forced the authorities to concentrate more resources, time and efforts on preventing the outbreaks from spreading and regaining a state of freedom from HPAI [27]. At the same time, Malaysia was actively involved in the MyanmarThailand-Malaysia (MTM) FMD eradication efforts, which may have further diverted limited resources. Consequently, surveillance activities were delayed for other diseases, including brucellosis, which thereafter led to an increased number of infected animals.

The proportion of sero-reactor herds remained relatively high $(26.8 \%)$ in the period of study. This phenomenon reflects the difficulty in achieving complete disease-free status for herds that were infected. It also strengthened the argument that perhaps a low percentage of reactor animals were missed during the surveillance or culling activities, which subsequently served as the source of propagation of the disease to other susceptible animals and herds.

The observed pattern of brucellosis reactors among the states could be ascribed to multiple factors. We suspect that the choice of farm management system may be 


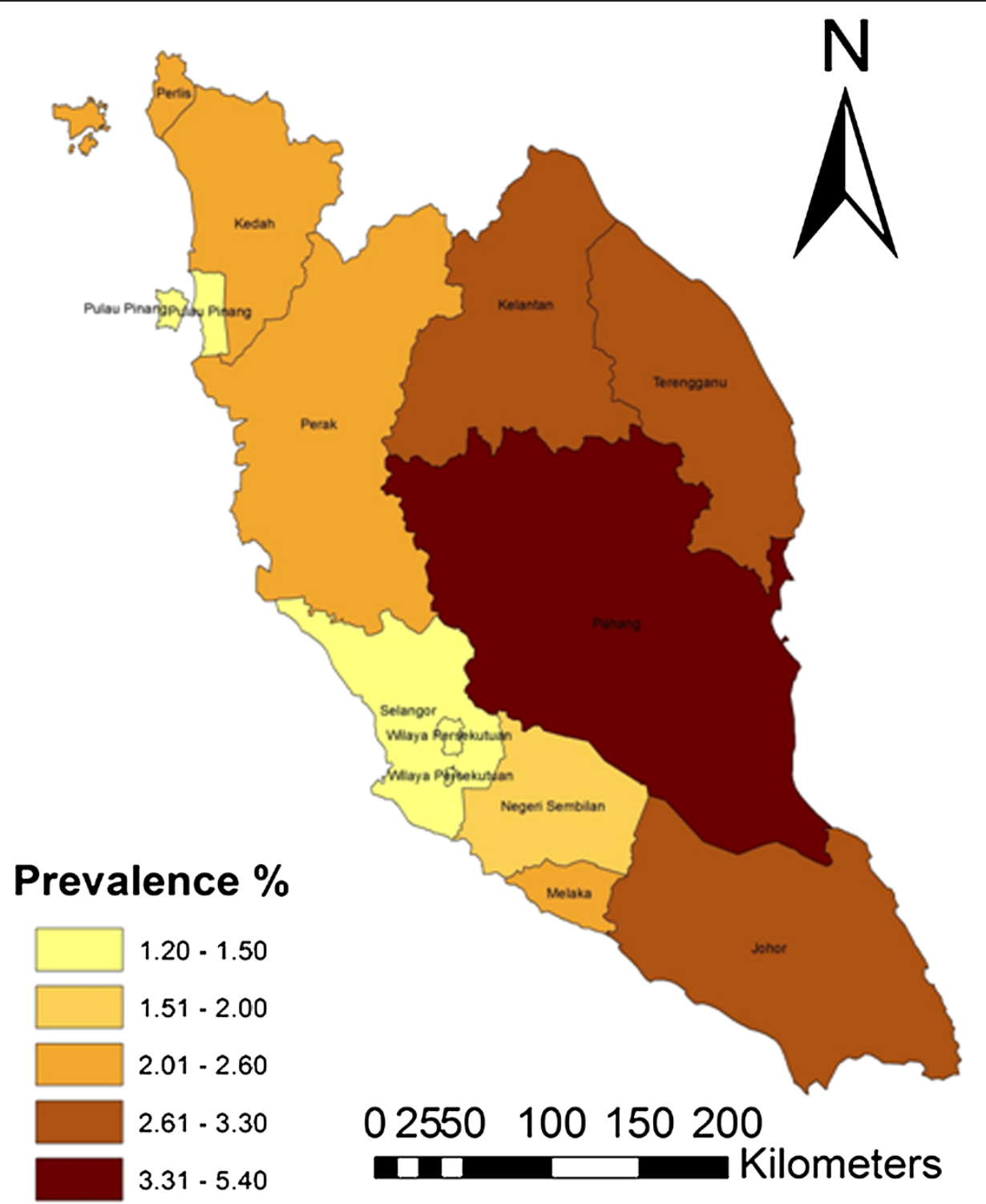

Figure 4 Choropleth map showing the overall prevalence of seropositive cattle in Peninsular Malaysia between 2000 and 2008.

the major reason for the differences; for example, integrated farming systems (integration of cattle and crops) are highly prevalent in Pahang and part of Johor and Kelantan [28]. In this type of system, animals belonging to various owners are raised extensively on the same plantation. The nature of the system makes herd health challenging and regular veterinary services inaccessible. However, as farm management information was not included in the surveillance information, we cannot arrive at a more definitive conclusion. We also believe that there may be variations in the vigorousness of the enforcement/culling of reactor animals among states due to various reasons including available resources, time, logistics, technical help and budgetary allocations [29]. Previous studies have reported that location, region or area has a significant correlation with brucellosis seropositivity, which, according to the authors, is attributable to management practices and other agro-ecological factors [3]. Moreover, the spatial distribution of bovine brucellosis further supports the claim/point that districts in the central part of the peninsula have higher herd-level and cattle-level seroprevalence compared to other parts. The spatial mapping of the sero-surveillance data in our study also uncovered several pockets of high seroprevalence existing within a few states with relatively lower herd and cattle-level seroreactors.

Our analysis of several putative herd-level factors associated with brucellosis from the surveillance data found that herd size, year of sampling, state and month of sampling were associated with herd-level seroprevalence 


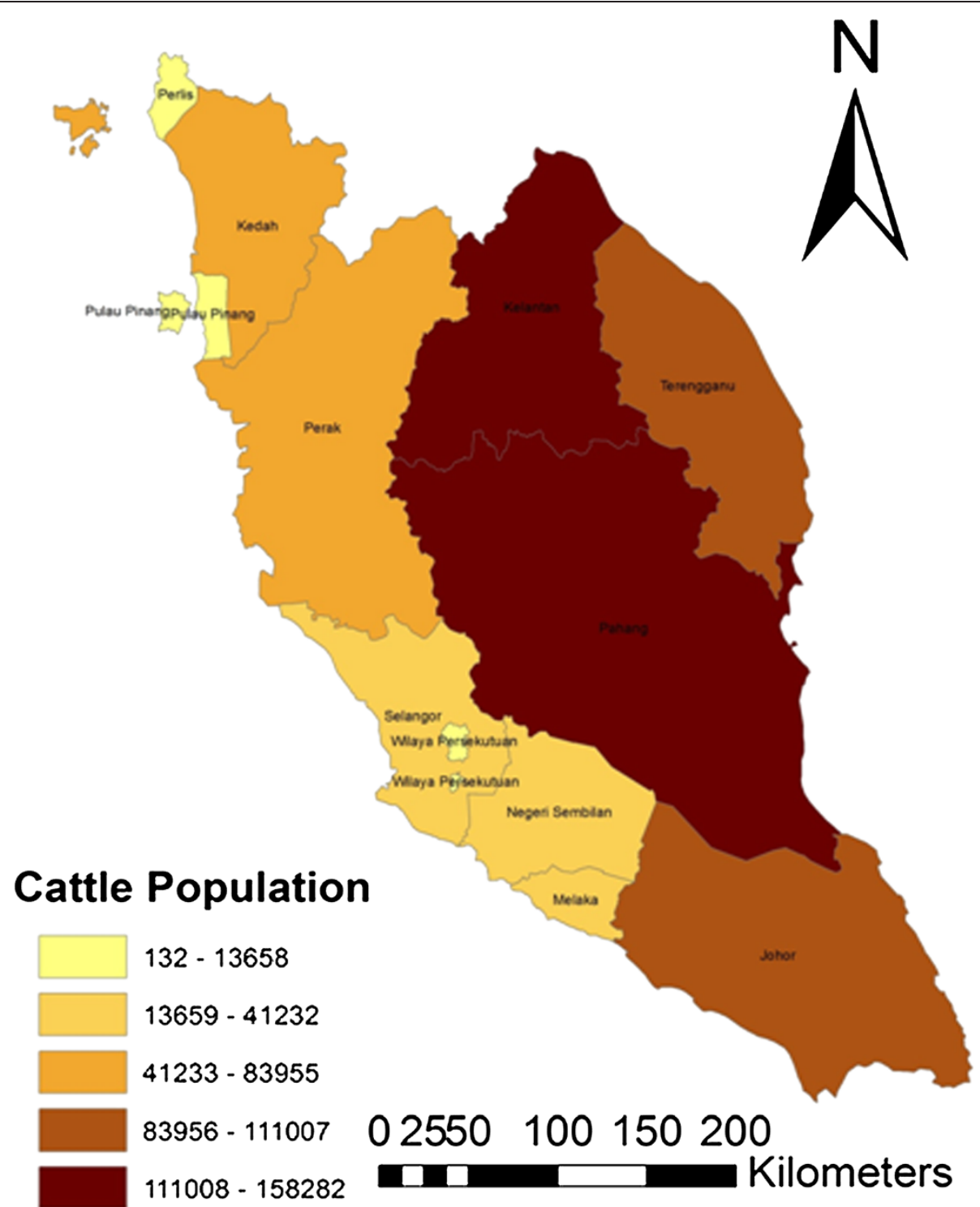

Figure $\mathbf{5}$ Choropleth map showing the cattle population of Peninsular Malaysia in 2008.

of bovine brucellosis in Peninsular Malaysia. Larger herds, in comparison to smaller ones, have a higher likelihood of seropositive cattle. The association of seropositivity with herd size is consistent with the results of other studies demonstrating this relationship [30,31]. Even though we do not have information on the stocking density of herd sampled in this study, we believe that there is a direct correlation between herd size and stocking density. An increase in herd size is accompanied by increased contact between animals, thus leading to cross infection [5]. This factor has been established as one of the important determinants of brucellosis seropositivity, especially given the occurrence of abortion or calving $[3,32]$.
Among the breeds, beef cattle appear to be at a higher risk. Brahman, Bali, Kedah Kelantan and Nellore cattle had a higher likelihood of being seropositive, while the dairy breeds, such as Friesien-Sahiwal and LID, had a significantly lower likelihood. We hypothesised that the major reason for this difference was the management system of the farm, because a large proportion of beef cattle in Peninsular Malaysia are raised in extensive systems, including the integrated farming system [17]. Extensive cattle management has been consistently reported by other authors to be an important risk factor for Brucella seroprevalence [33,34]. It is also possible that the difference was due to other confounding variables unaccounted for in this study. 
The association of month of sampling with seropositivity to Brucella infection is consistent with the findings of another study that reported rainfall or season to play an important role in the epidemiology of the disease [35]. In most parts of the peninsula, significantly higher rainfall occurs during the northeast monsoon from September until January (http://www.met.gov.my) and, accordingly, an increased likelihood of Brucella seropositivity was detected in the months of October to September in this study. Seasonal changes in the epidemiology of infectious diseases are common phenomenon in both temperate and tropical climates [36]. However, the mechanism of the change is poorly understood [36,37] and has been linked to the interaction of several intrinsic and extrinsic factors [36,38]. In the epidemiology of B. melitensis infection, seasonal factors have been reported to be associated with human brucellosis which, in most cases, coincide with the period of parturition among farm animals and, hence, increased exposure to farmers when attending to animals and consuming their milk [39]. In this study, we believe that extrinsic factors, such as rainfall and humidity may have contributed to the occurrence of the disease around this period, in combination with other environmental factors [38]. In addition, breeding of livestock and milk production are associated with the rainy season. Lending support to our observation, in cattle, $70 \%$ of births occur during rainfall [40]. This is accompanied by intensive shedding of Brucella organisms among infected animals with consequences of environmental contamination.

\section{Conclusions}

Our findings highlight the epidemiological features of bovine brucellosis via examination of serological evidence for the presence of the organism among cattle. Bovine brucellosis was widespread within Peninsular Malaysia where a possible cluster occurred in the central region of the peninsula where integrated farming systems were commonly practiced. The herd-level seroprevalence varied but remained high within the 9 years of study, while the cattle-level seropositive rates were comparatively low, but had a more subtle trend over the study period. We believe that the two patterns reflect the difficulty in achieving a herd free from brucellosis once infected; therefore, it is worth examining the mechanism of culling Brucella seroreactors as currently practiced to ensure a more efficient culling system. The high herd-level seroprevalence may impact the animal industry significantly as suggested in a limited study in Pahang, where the total cost associated with bovine brucellosis was RM 3.5 million, while the cost of potential loss to the beef industry was RM 21 million [41].

The decreasing rate of cattle sero-reactors from 2000 to 2004 was possibly due to a step-up and intensification of zoonotic disease surveillance activities by authorities following the Nipah disease outbreak in the late 1990s. However, the rate increased after 2004 until 2007, possibly due to a shift in resources and time allocations from this surveillance to the control of other pertinent diseases, depending on the global and local disease situations at the time. As with other studies that use disease serosurveillance data, our study was limited by the quality of the data available, including incomplete data from individual animals sampled and inconsistent formats of data recording resulting in inconsistent information. Notwithstanding our confidence in the results as they pertain to bovine brucellosis in Peninsular Malaysia, extensive inferences from the findings should only be made with knowledge about data deficiencies.

\section{Methods}

\section{Study area}

Malaysia $\left(4.1936^{\circ} \mathrm{N}, 103.7249^{\circ} \mathrm{E}\right)$ is located in Southeast Asia and comprises East Malaysia (Peninsular Malaysia) and West Malaysia (Sabah and Sarawak on Borneo Island). The two regions are separated by the South China Sea [42]. Peninsular Malaysia is comprised of 11 states and two federal territories and covers an area of 131,598 square kilometres bordering Thailand in the north and Singapore in the south. Peninsular Malaysia has an average rainfall of 2,400 $\mathrm{mm}$ and experiences hot and humid weather throughout the year with two monsoon seasons; the north-east monsoon from November to March and the south-east monsoon from May to September (http://www. met.gov.my). Malaysia has a relatively small cattle population size and within the years of study (2000-2008), the cattle population size ranged from 731,484 to 787,871 [43].

\section{Data sources}

Brucellosis serosurveillance activities were performed regularly by the state veterinary departments in Malaysia, as described in the Protokol Veterinar Malaysia Penyakit Brucella [29]. The program allows for serological screening of cows aged four months and above twice a year. Once confirmed, all seroreactors must be culled in the government abattoir. Slaughter under the supervision of the veterinary officer is required to ensure compensation of culled cattle.

The livestock sampling and serological testing for the serosurveilance programme was performed via the state's veterinary departments and its regional veterinary laboratories that are located throughout the peninsula. Accordingly, serum samples from cattle were tested for evidence of Brucella antibodies using the Rose Bengal Plate Test (RBPT) and the Complement Fixation Test (CFT), using the protocols and guidelines described by the OIE [44]. The confirmatory diagnosis for Brucella antibodies using the CFT was performed at the Veterinary 
Research Institute (VRI), Ipoh. The study was approved to be conducted by the Department of Veterinary Services, Putrajaya Malaysia.

We obtained data generated from the serological testing for bovine brucellosis from the Epidemiology and Surveillance Unit at the Department of Veterinary Services (DVS), Putrajaya, and the database at VRI, Ipoh, for years 2000 to 2008. These serosurveillance data have not been extensively analysed in the past. The data were compared and collated to improve their integrity. The data were thoroughly checked for accuracy in entry, coding and typing errors, and repeated entry of a farm in the course of one year was eliminated to ensure that a herd or farm was not overrepresented in a given year of study. The information obtained from the data includes farm names and addresses, date of sampling, location and state, breed, age range, number of animals tested and the number of animals within the tested herd.

\section{Data analysis}

The data were managed and stored in a Microsoft Excel ${ }^{\circ}$ (Microsoft Corporation) spreadsheet, and frequency tables were used to calculate prevalence based on state, year, herd, animal and breed. Seroprevalence rates over the 9 years were determined as the number of seropositive cattle divided by the total number of cattle sampled and confidence intervals were calculated at a 95\% level. The differences between/among proportions were tested using Chi-square and univariate logistic regression statistics. Herd size was categorised as $<20,20-40$ and $>40$. Age of animals on the farm was recorded as the range of the sampled animal's age within the herd and therefore cannot be further analysed to arrive at meaningful conclusions. All statistical analyses were performed using SPSS (version 16, Chicago, IL) at a significance level of $\alpha=0.05$.

\section{Spatial distribution}

A choropleth map was developed for herd- and cattlelevel seroprevalence of bovine brucellosis from 2000 to 2008 using the software Arc GIS v9.3 (ESRI, 2006). The results of the seropositive animals and herd were aggregated into an area (state) for the spatial analysis due to the lack of exact farm/herd coordinates and to maintain confidentiality of the farms. Additional datasets on the coordinates of the states and map of Malaysia were obtained from GIS data at the Department of Survey and Mapping Malaysia (JUPEM).

\section{Abbreviations}

HPAl: Highly pathogenic avian influenza; FMD: Foot and mouth disease; LID: Local Indian dairy; RBPT: Rose bengal plate test; CFT: Compliment fixation test; OIE: World Organization for Animal Health; VRI: Veterinary research institute; DVS: Department of Veterinary Service; JUPEM: Department of Survey and Mapping; Cl: Confidence interval; df: Degree of freedom;

Sd: Standard deviation; MTM: Malaysia Thailand Myanmar.
Competing interests

The authors declare that they have no competing interests.

\section{Authors' contributions}

MSA carried out the study, analysed the data and drafted the manuscript. LH conceived of the study, participated in its design, coordination and helped to draft the manuscript and approved the final draft. SKB participated in the design of the study and proof reading of the manuscript. RBM helped in acquiring the data, design of the study and proof reading of the manuscript. MAZ participated in the study design and proof reading of the manuscript. AA helped in acquiring the data, design of the study and proof reading of the manuscript. All authors read and approved the final manuscript.

\section{Acknowledgements}

The authors thank the Department of Veterinary Services Putrajaya and the Veterinary Research Institute, Ipoh for sharing and providing the data used in this study. We thank Katalin Bradford and Steven Krauss for reading and editing this manuscript.

\section{Author details}

${ }^{1}$ Department of Veterinary Pathology and Microbiology, Faculty of Veterinary Medicine, Universiti Putra Malaysia, UPM, Serdang 43400, Malaysia.

${ }^{2}$ Epidemiology and Surveillance Unit, Department of Veterinary Services, Putrajaya, Malaysia. ${ }^{3}$ Veterinary Research Institute, 59 Jalan Sultan Azlan Shah, Ipoh, Perak 31400, Malaysia. ${ }^{4}$ Department of Agribusiness and Information System, Faculty of Agriculture, Universiti Putra Malaysia, UPM, Serdang 43400, Malaysia.

Received: 27 February 2013 Accepted: 6 November 2013 Published: 18 November 2013

\section{References}

1. Godfroid J: Brucellosis in wildlife. Rev Sci Tech Off Int Epiz 2002, 21:277-286.

2. Gwida M, Al Dahouk S, Melzer F, Rösler U, Neubauer H, Tomaso H: Brucellosis- regionally emerging zoonotic disease? Croat Med J 2010, 51:289-295.

3. Megersa B, Biffa D, Niguse F, Rufael T, Asmare K, Skjerve E: Cattle brucellosis in traditional livestock husbandry practice in Southern and Eastern Ethiopia, and its zoonotic implication. Acta Vet Scand 2011, 53:24.

4. Abdussalam M, Fein DA: Brucellosis as a world problem. Dev Biol Stand 1984, 56:9-23.

5. Abernethy DA, Pfeiffer DU, Watt R, Denny GO, McCullough S, McDowell SWJ: Epidemiology of bovine brucellosis in Northern Ireland between 1990 and 2000. Vet Rec 2006, 158:717-721.

6. El Sherbini A, Kabbash I, Schelling E, El Shennawy S, Shalapy N, Elnaby GH, Helmy AA, Eisa A: Seroprevalences and local variation of human and livestock brucellosis in two villages in Gharbia Governorate. Egypt. Trans R Soc Trop Med Hyg 2007, 101:923-928.

7. NPC: Raw Goat Milk Sickens boys. National Poison Centre. Malaysia: University Sains; 2010. Available at http://www.prn.usm.my/poison_news.php?news_ id=6116 Retrieved $20^{\text {th }}$ February 2013.

8. Sam IC, Karunakaran R, Kamarulzaman A, Ponnampalavanar S, Syed Omar SF, Ng KP, Mohd Yusof MY, Hooi PS, Jafar FL, Abubakar S: A large exposure to Brucella melitensis in a diagnostic laboratory. J Hosp Infect 2012, 80:321-325.

9. Makita K, Fèvre EM, Waiswa C, Eisler MC, Welburn SC: How human brucellosis incidence in urban Kampala can be reduced most efficiently? A stochastic risk assessment of informally-marketed milk. PLOS ONE 2010, 5:e14188.

10. Seleem MN, Boyle SM, Sriranganathan N: Brucellosis: a re-emerging zoonosis. Vet Microbiol 2010, 140:392-398.

11. Joseph PG: Brucellosis in Malaysia. Tecnical report No. 4. Kuala Lumpur: Department of Veterinary Service, Ministry of Agriculture; 1987.

12. Bahaman $A R$, Joseph PG, Siti-Khairani B: A Review of the epidemiology and control of brucellosis in Malaysia. J Vet Malaysia 2007, 19:1-6.

13. Zainor HM: Isolation and characterization of Brucella abortus from cattle in Pahang, Master thesis. Malaysia: University Putra Malaysia, Pathology and Microbiology Department; 2010.

14. Robinson A: Guidelines for coordinated human and animal brucellosis surveillance. Rome: FAO animal production and health paper; 2003. 
http://www.fao.org/docs/eims/upload/215249/y4723e00.pdf Retrieved 20th February 2013

15. Joseph PG, Cheah PF, Arunasalam V, Tee Chin H: Studies on bovine brucellosis. I. Serum antibody response following calfhood vaccination with live S.19 and Kileed 45/20 adjuvant vaccine. Kajian Vet 1976, 8:63-68.

16. Joseph PG, Ham Thong Y: The typing of Brucella abortus isolates in Peninsular Malaysia. Kajian Vet 1979, 11:24-29.

17. Zainor M, Khairani-B S, Bahaman AR, Zunita Z: Isolation of Brucella abortus from aborted bovine fetus. Bangi-Putra Jaya, Malaysia: Proceedings of the 20th Congress of Veterinary Association Malaysia (published by Veterinary Association Malaysia); 2008.

18. Heng NH, Joseph PG: Eradication of brucellosis in cattle in Malaysia and its public health. Kajian Vet 1986, 18:255-260.

19. Madjid A: Epidemiology of Brucellosis in Smallholder Cattle Herds in South Sulawesi, Indonesia. Copenhagen, Denmark: Proceedings of the 5th International Symposium on Veterinary Epidemiology and Economics (published as ActaVeterinaria Scandinavica Supplementum 84); 1988.

20. Jittapalapong S, Inpankaew T, Sangwaranond A, Phasuk C, Pinyopanuwat N, Chimnoi W, Kengradomkij C, Sununta C, Arunwipat P: Current status of brucellosis in dairy cows of Chiang Rai Province, Thailand. Kasetsart J (Nat Sci) 2008, 42:67-70.

21. Al-Majali AM, Talafha AQ, Ababneh MM, Ababneh MM: Seroprevalence and risk factors for bovine brucellosis in Jordan. J Vet Sci 2009, 10:61-65.

22. Medeiros AMB, Junior IAN, Mathias LA: Prevalence of bovine brucellosis among milk suppliers of a dairy industry in Itirapuã, São Paulo, Brazil. Ars Veterinaria 2011, 27:152-160.

23. Megersa B, Biffa D, Abunna F, Regassa A, Godfroid J, Skjerve E: Seroprevalence of brucellosis and its contribution to abortion in cattle, camel, and goat kept under pastoral management in Borana, Ethiopia. Trop Anim Health Prod 2011, 43:651-656.

24. Holt HR, Eltholth MM, Hegazy YM, El-Tras WF, Tayel AA, Guitian J: Brucella spp. infection in large ruminants in an endemic area of Egypt: crosssectional study investigating seroprevalence, risk factors and livestock owner's knowledge, attitudes and practices (KAPs). BMC Public Health 2011, 11:341.

25. Mai $H$, Irons $P$, Thompson P: A large seroprevalence survey of brucellosis in cattle herds under diverse production systems in northern Nigeria. BMC Vet Res 2012, 8:144

26. Rahman SA, Hassan SS, Olival KJ, Mohamed M, L-Y Chang Y, Hassan L, Saad NM, Shohaimi SA, Mamat ZC, Naim MS, Epstein JH, Suri AS, Field HE, Daszak P: Characterization of Nipah virus from naturally infected Pteropus vampyrus bats, Malaysia. Emerg Infect Dis 2010, 16:16-19.

27. Sharifah SH MNS, Hassuzana K, Omar AR, Aini I: Avian Influenza: Managing Risk and Responses in Malaysia. Kuala Lumpur, Malaysia: Proceedings of the 17th Congress of Veterinary Association Malaysia (published by Veterinary Association Malaysia); 2005

28. Ramzi BI: Performance of FELDA plantation Sdh Bhd Contractors, Master Thesis. Universiti Technologi Malaysia Skudai Johore, Construction Management Department; 2006.

29. DVS: Protokol Veterinar Malaysia, Penyakit Brusela. Protokol Veterinar Malaysia. Malaysia: Department of Veterinary Services, Ministry of Agriculture; 2008

30. Muma JB, Samui KL, Oloya J, Munyeme M, Skjerve E: Risk factors for brucellosis in indigenous cattle reared in livestock-wildlife interface areas of Zambia. Prev Vet Med 2007, 80:306-317.

31. Mekonnen H, Shewit K, Moses K: Serological survey of bovine brucellosis in barka and arado breeds (Bos indicus) of Western Tigray, Ethiopia. Prev Vet Med 2010, 94:28-35.

32. Omer MK, Skjerve E, Woldehiwet Z, Holstad G: Risk factors for Brucella spp. infection in dairy cattle farms in Asmara, State of Eritrea. Prev Vet Med 2000, 46:257-265.

33. Berhe G, Belihu K, Asfaw Y: Seroepidemiological investigation of bovine brucellosis in the extensive cattle production system of Tigray Region of Ethiopia. Intern J Appl Res Vet Med 2007, 5:65-71.

34. Silva I, Dangolla A, Kulachelvy K: Seroepidemiology of Brucella abortus infection in bovids in Sri Lanka. Prev Vet Med 2000, 46:51-59.

35. Muñoz PM, Boadella M, Arnal M, de Miguel MJ, Revilla M, Martínez D, Vicente J, Acevedo P, Oleaga A, Ruiz-Fons F, Marín CM, Prieto JM, de la Fuente J, Barral M, Barberán M, de Luco DF, Blasco JM, Gortázar C: Spatial 404 distribution and risk factors of Brucellosis in Iberian wild ungulates. BMC infect Dis 2010, 10:46.
36. Grassly NC, Fraser C: Seasonal infectious disease epidemiology. Proc $R$ SoC B 2006, 273:2541-2550

37. Altizer S, Dobson A, Hosseini P, Hudson P, Pascual M, Rohani P: Reviews and synthesis: seasonality and the dynamics of infectious diseases. Ecol Lett 2006, 9:467-484

38. Pascual M, Dobson A: Seasonal patterns of infectious diseases. PLoS Med 2005, 2:e5.

39. Corbel M: Brucellosis in humans and animals. Geneva(Switzerland): WHO, FOA,OIE; 2006. http://www.who.int/csr/resources/publications/Brucellosis.pdf Retrieved 20th Febuary 2013

40. Mwebe R, Nakavuma J, Moriyón I: Brucellosis seroprevalence in livestock in Uganda from 1998 to 2008: a retrospective study. Trop Anim Health Prod 2011, 43:603-608.

41. Azmie MZ, Mohd Z, Abidin AZ, Rohaya Mohd A: Use of GIS in Brucellosis Eradication Programme in Pahang. Kuala Lumpur, Malaysia: Proceedings of the 17th Congress of Veterinary Association Malaysia (published by Veterinary Association Malaysia); 2005

42. NRE: Malaysia Second National Communication to the UNFCCC 2011. http:// www.nre.gov.my/Malay/Alam-Sekitar/Documents/Penerbitan/SECOND\% 20NATIONAL\%20COMMUNICATION\%20TO\%20THE\%20UNFCCC\%20(NC2). pdf Retrieved 20th Febuary 2013.

43. DVS: Cattle population by state. Livestock. Kementerian Pertanian dan Industri Asas Tani Malaysia; 2011. Available at http://www.moa.gov.my/c/ document library/get file?uuid=851fc0ee-240c-4cab-b977d37e0ca37992\&groupld=43204 Retrieved 20th Febuary 2013.

44. OIE: Manual of Diagnostic Tests and Vaccines for Terrestrial Animals: Bovine brucellosis, Version adopted by the World Assembly of Delegates of the OIE in May 2009. http://www.oie.int/fileadmin/Home/eng/Health_standards/ tahm/2.04.03_BOVINE_BRUCELL.pdf Retrieved 20th February 2013.

doi:10.1186/1746-6148-9-230

Cite this article as: Anka et al:: Bovine brucellosis trends in Malaysia between 2000 and 2008. BMC Veterinary Research 2013 9:230.

\section{Submit your next manuscript to BioMed Central and take full advantage of:}

- Convenient online submission

- Thorough peer review

- No space constraints or color figure charges

- Immediate publication on acceptance

- Inclusion in PubMed, CAS, Scopus and Google Scholar

- Research which is freely available for redistribution

Submit your manuscript at www.biomedcentral.com/submit
C BioMed Central 